\title{
Estimating apparent survival of sub-adult and adult white sharks (Carcharodon carcharias) in central California using mark-recapture methods
}

\author{
Paul E. Kanive ${ }^{1 *}$, Jay J. Rotella ${ }^{1}$, Salvador J. Jorgensen ${ }^{2}$, Taylor K. Chapple ${ }^{3}$, \\ Scot D. Anderson ${ }^{2}$, A. Peter Klimley ${ }^{4}$ and Barbara A. Block ${ }^{3}$ \\ ${ }^{1}$ Department of Ecology, Montana State University, Bozeman, MT, USA, ${ }^{2}$ Monterey Bay Aquarium, Monterey, CA, USA, \\ ${ }^{3}$ Department of Biology, Hopkins Marine Station, Stanford University, CA, USA, ${ }^{4}$ Wildlife, Fish and Conservation, University of \\ California, Davis, Davis, CA, USA
}

OPEN ACCESS

Edited by:

Rob Harcourt,

Macquarie University, Australia

Reviewed by:

Clive Reginald McMahon,

University of Tasmania, Australia Leslie New,

Washington State University, USA

Nuno Queiroz,

University of Porto, Portugal

*Correspondence:

Paul E. Kanive,

Department of Ecology, Montana State University, PO Box 173460, Bozeman, MT 59717-3460, USA

paul.kanive@msu.montana.edu

Specialty section: This article was submitted to Marine Megafauna, a section of the journal Frontiers in Marine Science

Received: 30 December 2014 Accepted: 17 March 2015 Published: 01 April 2015

Citation:

Kanive PE, Rotella JJ, Jorgensen SJ, Chapple TK, Anderson SD, Klimley AP and Block BA (2015) Estimating apparent survival of sub-adult and adult white sharks (Carcharodon carcharias) in central California using mark-recapture methods.

Front. Mar. Sci. 2:19

doi: 10.3389/fmars.2015.00019
Quantifying life history parameters of marine top predators is challenging, as observations are difficult and uncertainty in sex assignment can confound the determination of sex specific parameters. However, these parameters are critical for accurate population assessments and understanding of population dynamics. Using mark recapture observations at white shark foraging aggregation sites, we tested for differences in survival between sexes and estimated apparent survival for sub-adult and adult white sharks in neritic waters off central California. We used 6 years of mark-recapture data and a model that accounted for imperfect detection and imperfect sex assignment. Empirical information based on direct observations suggests that there are no sex-specific or temporal differences in survival during the study period and that survival was estimated to be 0.90; $\mathrm{SE}=0.04$. Additionally, after animals whose sex was unknown throughout the study period were probabilistically assigned to sex, the ratio in this sample is estimated to be 2.1 males for every female observed. This estimated ratio is lower than the observed ratio of $3: 1$. We demonstrate that the estimated capture probability for males was roughly twice as high as that for females $(0.41, \mathrm{SE}=0.06$ and 0.19 , SE $=0.07$ respectively). Together these results suggest (1) that the sex ratio is uneven but not as skewed as uncorrected observation data would suggest and (2) that unequal mortality in older age classes are not the cause of the observed sex bias but more likely results from disparate mortality earlier in life or differences in behavior. Future research is needed to explore the potential causes of the observed sex bias.

\section{Keywords: mortality rate, imperfect sex assignment, sex ratio, imperfect detection, LOLASURVIV}

\section{Introduction}

Sharks play critical roles in top-down regulation of marine ecosystems (Ferretti et al., 2010; Estes et al., 2011). The white shark (Carcharodon carcharias) is a top consumer in oceanic and neritic ecosystems. Currently, little empirical data exist to estimate vital rates or population dynamics of 
this species due to challenges inherent in studying a large pelagic predator. White sharks are long-lived, late to mature, and produce few young making them vulnerable to overexploitation (Cailliet et al., 1985; Francis, 1996; Chapple and Botsford, 2013; Andrews and Kerr, 2015; Hamady et al., 2014). White sharks are protected internationally under the Convention on International Trade in Endangered Species (CITES, Appendix II) and listed as vulnerable under the World Conservation Union Red List (IUCN, Category VU A1cd+2cd) (Dulvy et al., 2008).

Recent genetic studies have shown that the northeastern Pacific (NEP) white shark population is genetically distinct from other known white shark populations in South Africa, AustraliaNew Zealand, Northwest Pacific, Northwest Atlantic, and the Mediterranean (Pardini et al., 2000; Gubili et al., 2010, 2012; Jorgensen et al., 2010; Tanaka et al., 2011). Electronic tags have shown that NEP sub-adult (sharks $>2.4 \mathrm{~m}$ total length (TL) but not mature) and adult white sharks [females $>4.5 \mathrm{~m}$ TL (Francis, 1996) and males $>3.8 \mathrm{~m}$ TL (Pratt, 1996)] aggregate annually at two primary sites in the California Current: central California, USA (Klimley, 1985; Klimley and Anderson, 1996) and Guadalupe Island, Mexico (Domeier and Nasby-Lucas, 2008). Tracks generated from time series data recorded on pop-up satellite archival tags (PAT) indicate that both groups make similar and predictable offshore migrations into the subtropical gyre to a geographic area known as the "White Shark Café" (Weng et al., 2007a; Jorgensen et al., 2010) located approximately 2200 kilometers west of the northern portion of the Baja Peninsula (Domeier and Nasby-Lucas, 2008; Jorgensen et al., 2010). In addition, white sharks tagged in the NEP neritic foraging areas travel as far west as the Hawaiian Archipelago (Boustany et al., 2002; Weng et al., 2007a; Domeier and Nasby-Lucas, 2008; Jorgensen et al., 2010). To date, there are few data indicating that sharks visit both coastal aggregation sites off the North American coast but some migratory exchange is evident from acoustic tag information (Jorgensen et al., 2012b).

Satellite tagging has been combined with acoustic tagging data in the central California aggregation sites, which together have revealed that these annual migrations of white sharks inclusive of an onshore and offshore phase are predictable and repeatable. Males show a consistent "to and from" annual migration from coastal aggregation sites at central California to the White Shark Café and/or Hawaii and back. In contrast, females spend more time offshore, have a more expansive range, which includes more southerly coastal locations than those used by males (Klimley, 1985; Jorgensen et al., 2012a). After sharks experience offshore movements, tagging data indicates sharks of both sexes return to central California (Jorgensen et al., 2010). This migratory behavior supports the use of a mark-recapture framework for estimation of population parameters at coastal sites (Chapple et al., 2011). Several studies have demonstrated that the pattern on the trailing edge of the white shark first dorsal fin is stable over many years and can be used as a means of identifying individuals, i.e., serves as a natural "mark" (Gubili et al., 2009; Anderson et al., 2011; Towner et al., 2013). The population trend remains unknown in central California although interpretations of catch per unit effort data of young of the year white sharks in Southern
California have been taken to suggest an increasing trend in the smaller length classes ( $<2 \mathrm{~m}$ ) (Lowe et al., 2012).

Mark recapture studies (Chapple et al., 2011; Sosa-Nishizaki et al., 2012) at both California Current aggregation sites indicate the sex ratio of sub-adult and adult white sharks is apparently skewed toward males at the coastal aggregation sites of central California and Guadalupe Island. Chapple et al. (2011) observed a ratio of 3.6:1 (69 males: 19 females). It should be noted that an additional 42 individuals were observed but could not be assigned to sex during the 3-year study making it impossible without further analysis to accurately assess the actual sample sex ratio. This uncertainty is especially interesting, given that SosaNishizaki et al. (2012) observed a much more even sex ratio of 1.5:1 (67 males: 46 females) at Guadalupe Island in a 9-year study with no unknown sexed animals in their sample dataset. A recent abundance estimate of California Current white sharks (Dewar et al., 2013) assumed a 1:1 sex ratio although neither empirical dataset from central California or Guadalupe Island suggests this to be true. Outside of an observed $\sim 1: 1$ sex ratio at birth (Uchida et al., 1996), there are no data to suggest equal numbers of older (sub-adult and adult) males and females. A skewed ratio may in fact be true, a critical consideration for population studies. First, inflating the number of females to equal males could falsely increase the population (requiring there to be more females than evident in the data set) and may ignore underlying behavioral or physiological causes of the bias (affecting management and conservation efforts). Also, as females are likely a more important demographic for population trend and viability than males, artificially overinflating the number of females to establish parity with males could overestimate reproductive potential of the population and resilience to perturbation. Therefore, it will be important to determine if the observed skewed sex ratio at both central California and Guadalupe Island is in fact real.

The strongly skewed observed sex ratio for sharks in the California population could be a result of two very different processes. First, sex-specific behavioral differences could make females less likely to be sampled, which would bias the observed sex ratio away from the true ratio. Second, demographic differences could be at least partially responsible for the skewed sex ratio if mortality rates are higher for females. For example, migratory differences could expose females to greater mortality risks. Clearly, understanding the extent to which the observed skew in sex ratio is apparent (due to behavioral differences) or real (due to survival differences) is crucial for our evaluation of white shark population dynamics and management.

Because white sharks have a slow life history and survival of mature sharks is expected to be important to population persistence, disparate mortality in males and females could have important population level consequences and effect how this group is managed and assessed. To date, the only survival rate estimates that exist were developed with ad hoc methods (Smith et al., 1998; Cortés, 2002), and nothing is known about potential differences in mortality rates between the sexes. Clearly there is strong need to obtain survival rates and test for differences between sexes using rigorous estimation methods and multiple years of empirical data. An understanding of annual survival could be an important step toward gaging the sustainability of this population and 
used in predictive models to assess status (i.e., population viability analyses). Additionally, survival rates can inform current management strategy as to the effectiveness of current protective measures for white sharks off central California.

Annual apparent survival rates estimate the proportion of the population that will survive, on average, from 1 year to the next. The complement of apparent survival rate (i.e., 1 - apparent survival rate) includes an estimate of mortality and permanent emigration, or what proportion of the population is lost on average over the course of a year. However, when estimating survival rates, sex-based differences in survival could be obscured if sampling regimes do not explicitly account for differential detection probability (Lebreton et al., 1992). White sharks can be assigned to sex when visually observed in an aggregation site by noting the presence of claspers on males or absence of claspers for females. However, the probability of assigning sex is unequal, as it is easier to positively identify presence of claspers than confirm their absence (Chapple et al., 2011). Nichols et al. (2004) developed a model to test for differences in apparent survival between sexes when imperfect sex assignment occurs on sampling occasions, a viable model that can be used across taxa. Additionally, this model estimates the sex ratio of the sample population after probabilistically assigning sex to animals of unknown sex.

In this study, we used empirical mark-recapture data from 6 years at central California aggregation sites to estimate the apparent survival rates specific to this group of white sharks. The new model enabled testing if the observed skewed sex ratio of sub adult and adult sharks at coastal aggregation sites in central California is a result of disparate apparent survival rates, while accounting for imperfect detection and imperfect sex assignment.

\section{Materials and Methods}

\section{Study Area and Data Collection}

Sampling effort in this study was focused at known sub-adult and adult white shark aggregation sites along the central California coast during periods of peak residency from 2006 to 2011 [Figure 1; Southeast Farallon Island (From 2006 to 2011), Tomales Point (From 2006 to 2011), and Año Nuevo Island (2011)]. Several independent lines of evidence, such as electronic tagging, visual identification of unique fin structure, and human-shark interactions indicate that white sharks are present at these central California sites from late July-February (Klimley and Anderson, 1996; Long et al., 1996; McCosker and Lea, 2006; Jorgensen et al., 2010; Anderson et al., 2011).

White sharks were observed during natural predation events or were attracted to $4.6-5.9 \mathrm{~m}$ research vessels using a floating, seal-shaped decoy $\sim 1 \mathrm{~m}$ in length in tandem with a small $(1-5 \mathrm{~kg})$ piece of salvaged marine mammal blubber (Physeter macrocephalus, Megaptera novaeangliae, Balaenoptera physalus, Mirounga angustirostris, Phoca vitulina, or Zalophus californianus) tethered to the vessel. The decoy was floated $\sim 10 \mathrm{~m}$ off the stern of the vessel attached via $36 \mathrm{~kg}$ test monofilament to a fishing pole. The decoy served as a visual attractant for the shark to inspect, and the blubber created a localized scent around the research vessel to offset any natural inhibition the shark might have to coming close to the vessel.

White shark dorsal fins are unique to individuals, and the photographed features have been shown to persist $>20$ years (Anderson et al., 2011). Therefore, in this study, the dorsal fin was used as a "mark." High-resolution photographs were taken

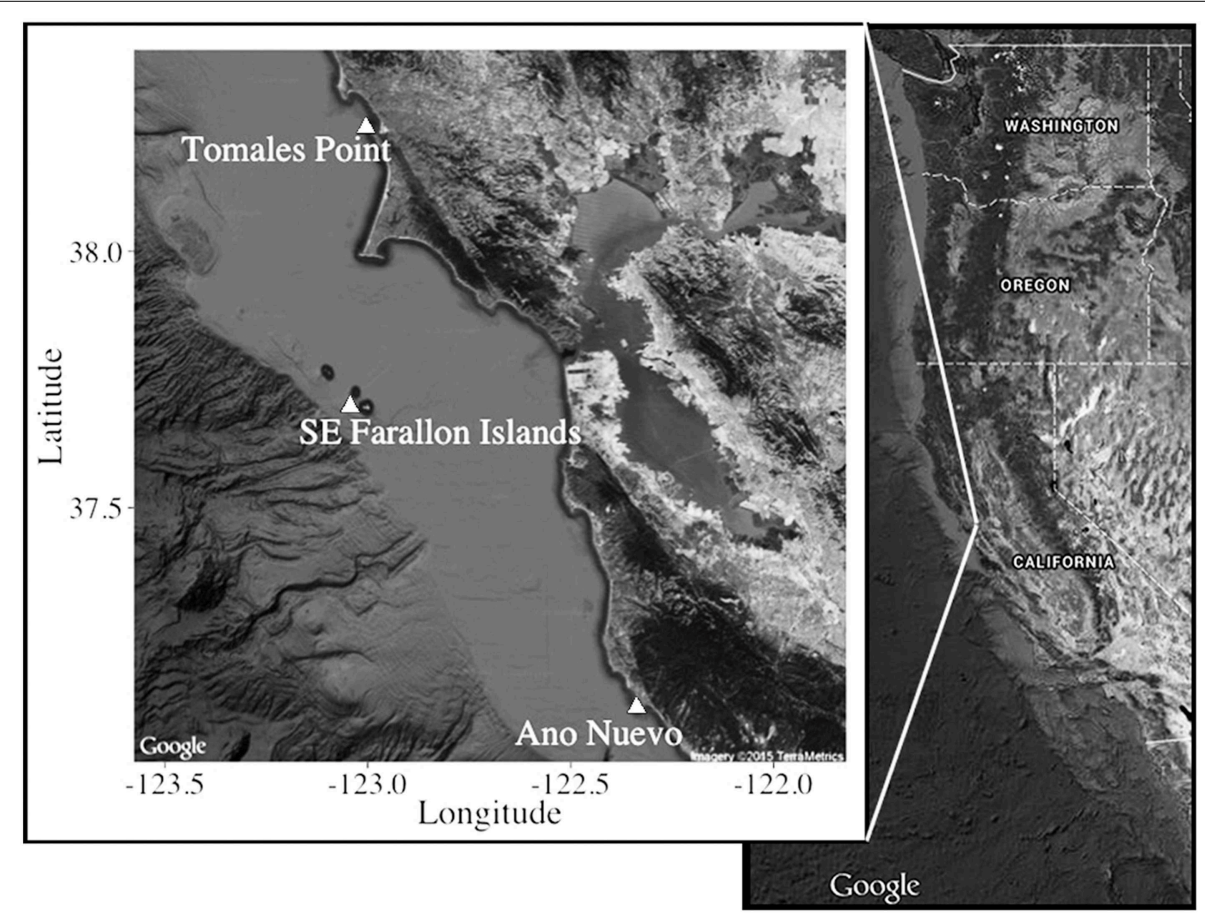

FIGURE 1 | Sampling locations off central California. 
of the dorsal fin above the surface of the water. If a shark did not surface but could be seen in the water near the vessel, an underwater HD video camera attached to a pole was used to collect high-definition still images of the dorsal fin and determine the presence (male) or absence (female) of claspers located posterior to the pelvic fins to determine sex. These methods favored sex assignment of males because it was easier to confirm the presence of claspers than to confirm their absence. Any uncertainty in sex assignment resulted in an individual's sex being recorded as unknown until such time as it was definitively determined during a subsequent encounter. For most sharks, especially those encountered in multiple years, sex was eventually determined. For some, sex was never determined. Approximate lengths of sharks were recorded when a shark swam close to the research vessel, which was of a known length.

Over the course of the study, the set of white shark dorsal fin photos obtained that met the identification standard described by Chapple et al. (2011) were used to develop individual markrecapture encounter histories. These resighting histories indicated whether or not each individual shark had been seen or not in each year of the study and whether or not the sex of the animal was known or not when the animal was encountered. Each time we obtained a new fin photo, researchers experienced with matching fin photos checked to see if it matched a previously cataloged fin photo. If there was no match, the fin photo was cataloged as representing a new individual. An individual was considered "marked" in the field season when it was first identified, and "recaptured" in each subsequent field season when its dorsal fin was successfully photographed. Sampling occasions were thus defined as the annual field seasons, which ran from September of year $t$ to February of year $t+1$, and each was referenced by year $t$ (e.g., 2006 season was Sept. 2006-Feb. 2007).

\section{Data Analysis}

The encounter history for each shark provided information on whether the individual was observed or not in each occasion, i.e., year. In the encounter histories, information on what was known about the sex of the individual was recorded on each sampling occasion $(0=$ shark not seen on given occasion, $U=$ shark seen on given occasion but sex was unknown based on this and all previous sightings, $\mathrm{M}$ or $F=$ shark seen on given occasion and sex was unambiguously assigned on this and/or a previous occasion).

To develop unbiased estimates of annual survival rate from the mark-recapture data collected, it was necessary to adjust for imperfect detection of sharks (Williams et al., 2002) and to properly handle the fact that some individuals were of unknown sex for the duration of the study. To avoid these potential biases, a method (specifically Method B) was used that was developed by Nichols et al. (2004). The method is an extension of the CormackJolly-Seber (Cormack, 1964; Jolly, 1965; Seber, 1965), which was designed to estimate apparent survival rate $(\varphi$, the probability of remaining alive from 1 year to the next and not permanently emigrating) from encounter histories where sex is known for some but not all individuals and sex-specific estimates of $\varphi$ are of interest. With this approach, encounter histories provide information on when animals were observed or not and what was known about their sex on each of the occasions when they were observed. As an example, the history 0UMM0M provides information for a shark that was first observed on occasion 2 when insufficient evidence was obtained to verify sex. It was observed again on occasion 3 and determined to be male. Consequently on occasions 4 and 6 when the animal was observed again, sex was automatically assigned regardless of whether claspers were observed on those occasions because sex is a permanent attribute that does not change among occasions. Model parameters estimated by this approach involve survival and detection as well as additional parameters related to sex ratio and sex assignment. The parameters are defined by Nichols et al. (2004) as:

$\varphi_{i}^{s}=$ probability of apparent survival from occasion $i$ to $i+1$ for animals of sex $s$, wheres $\in\{\mathrm{M}, \mathrm{F}\}$,

$p_{i}^{s}=$ probability of capture in period $i$ for animals of sex $s$, where $s \in\{\mathrm{M}, \mathrm{F}\}$,

$\delta_{i}^{s}=$ probability that sex is determined in period $i$ for a animal of sex $s$ that is captured in period $i$, where $s \in\{\mathrm{M}, \mathrm{F}\}$,

$\pi_{i}=$ probability that an animal first released in period $i$ is a male.

Because no published studies exist on annual survival rates for the central California group of white sharks using mark-recapture data, an exploratory approach was used to develop a list of candidate models. For $\varphi$ and $p$, models were considered that either held the parameter constant (.) or let it vary by year $(t)$, sex $(s)$, or both [additive $(t+s)$ or interactive $(t \times s)$ ]. Models were fit that either let $\pi$ vary among years $(t)$ or held it constant (.). For $\delta$, models were fit for which the parameter varied by sex $(s)$, time $(t)$, or both $(t+s$ or $t \times s)$. All-possible combinations were considered of the models for each of the 4 parameters, which resulted in 150 candidate models. Analyses were conducted using the software program LOLASURVIV (Nichols et al., 2004). Akaike's Information Criterion corrected for small sample sizes (AICc) was used to evaluate the support from the data for each of the models (Burnham and Anderson, 2002). When evaluating model-selection results, estimates were reviewed to identify competing models containing uninformative parameters (Arnold, 2010) where a model $\sim 2 \Delta$ AICc units away from the top model that has one more parameter and essentially the same values of the maximum log-likelihood indicate that the extra parameter is uninformative to an otherwise good model (Burnham and Anderson, 2002) and were therefore deemed redundant.

The dataset was too sparse to test for goodness-of-fit using Chi-square within LOLASURVIV. Fortunately, Program MARK (White and Burnham, 1999) has alternative tests that go beyond what's available in LOLASURVUV. We used the median $\hat{c}$ approach that's commonly used in many mark-recapture studies and uses simulation to evaluate overdispersion. This approach evaluates possible issues with goodness-of-fit due to lack of independence or missing covariates. The value of $\hat{c}$ or overdispersion, if it is much larger than 1 but less than 3 , can be used to inflate variances in the resulting estimates to account for the issues in an omnibus way. If $\hat{c}>3-4$, there is cause to consider other model structures or additional covariates as there is evidence of important missing covariates and serious issues of goodness-of-fit. Because models in Program MARK could not accommodate the uncertain sex issue, we evaluated 3 different 
versions of our dataset where sex was assigned. The 3 versions bracket the range of possible conditions that might exist in terms of (1) unknown sex animals and (2) sex-specific parameter values. Given our results regarding sex-specific differences in $\varphi$ and the probability of sex determination for males vs. females (see Results), we believe that we did bracket conditions well for our situation and were able to evaluate goodness-of-fit. In the first 2 versions, unknowns were considered to be 1 ) all females ( $\varphi$ and $p$ were sex specific in the model evaluated) or 2) all males ( $\varphi$ and $p$ were sex specific in the model evaluated). In the $3 \mathrm{rd}$ version of the dataset, unknowns, males, and females were pooled and $\varphi$ and $p$ were held constant for all individuals in the model evaluated. We assume that if substantial overdispersion exists in our data, then it would be identified in one of these diagnostic tests because the approach we used does evaluate evidence of overdispersion in the way $\varphi$ and $p$ are modeled across sexes and years in a model structure very similar to what we used in LOLASURVIV.

Though Chapple et al. (2011) did not find evidence of temporary emigration (TE) during their shorter study period it was considered that females might have temporarily emigrated from the study area during our longer 6-year study period. This is important because when TE is non-random (Markovian), i.e., animals have a different probability of being a temporary emigrant in year $t+1$ depending on whether they are already a temporary emigrant in year $t$ or not, CJS estimates of $\varphi$ can be biased (Kendall et al., 1997). However, if TE is completely random with respect to an animal's current emigration status, estimates of $\varphi$ remain unbiased (Schaub et al., 2004; Rotella, 2009). To test for evidence of whether TE for females in our data might have been random or Markovian (Schaub et al., 2004), Test 2.CT of Program UCARE (Choquet et al., 2009) was used. Test 2.CT is usually a diagnostic tool to detect trap response behavior (trap-shy or traphappy). However, Schaub et al. (2004) demonstrated that Test 2.CT could be utilized to detect Markovian temporary emigration. We ran two tests: one based on data for all known adult $(>4.5 \mathrm{~m})$ females and another for all known females $(>2.4 \mathrm{~m})$ to test whether Markovian temporary emigration could be detected.

\section{Results}

From 2006 to 2011, 1926 h of observation over 403 days were spent at three discrete central California locations (Southeast Farallon Island, 85 days, $424 \mathrm{~h}$; Tomales Point, 302 days, $1414 \mathrm{~h}$; Año Nuevo Island, 16 days, $88 \mathrm{~h}$ ). We identified 199 individual white sharks from 668 high-quality fin-ID's over the course of the study. The observed ratio of males to females was heavily skewed (3.0:1 respectively), and $13.6 \%$ of the individuals were of unknown sex (129 Male; 43 Female; 27 Unknown). Total estimated length averaged $4.1 \mathrm{~m}(\mathrm{SD}=0.7 \mathrm{~m}$, range $=2.4-5.5 \mathrm{~m}$, $n=187)$.

Results of the median c procedure testing for overdispersion in the data indicated that overdispersion was low and not a concern for the analyses as $\mathrm{c}$ from all three models evaluated were $<1.19$. Therefore, AICc was used to evaluate the support from the data for the competing models considered. No evidence was found to suggest that TE by females was Markovian. In our tests for randomness (Test 2.CT in U-CARE), there was insufficient evidence to reject the null hypothesis that TE in adult females and all females was random, $\left(X^{2}=2.20, d f=3\right.$, two-sided $p$-value $=0.51 ; X^{2}=3.54, d f=3$, two-sided $p$-value $=0.75$ respectively). Based on these results, we concluded that modeling in LOLASURVIV was appropriate.

Three models of the 150 run (for complete list, see Supplementary Material) received support from the data $(\triangle \mathrm{AICc}<5.0$, Table 1). Of those, in the best-supported model ( 0.90 relative weight), $\varphi$ was the same for male and female sharks and constant across all years, $p$ differed by sex but not by year, $\pi$ was held constant, and $\delta$ differed by sex and by year (additive form, sex $+\mathrm{t}$ ). Among those models containing no uninformative parameters, no other model was well supported by the data ( $\triangle \mathrm{AICc}$ values $>4.47$ for all other models). In the top model, $\varphi$ for males and for females was estimated as $0.90(95 \% \mathrm{CI}=0.81-0.98)$. The best-supported model estimated $p$ as $0.41(95 \% \mathrm{CI}=0.30-0.52)$ for males and $0.19(95 \% \mathrm{CI}=0.06-0.33)$ for females.

Estimates of $\delta$ were higher for males than females and tended to increase over time, especially for females (Figure 2). The sex ratio of the sample of sharks for which fin-ID photos were obtained was skewed in favor of males with $\pi$ estimated as 0.68 $(95 \% \mathrm{CI}=0.57-0.78)$. This point estimate of the sample sex ratio is lower than the observed sex ratio of 0.75 based on observed data where 172 sharks whose sex was determined but that ignores the possibility that females might be harder to assign to sex.

Models in which $\varphi$ differed for males and females were not well supported. In the best-supported version of such models, the coefficient that distinguished between $\varphi$ for males and females was deemed a redundant parameter (Table 1). Further, in such models, sex-specific survival rates were very similar to each other and the respective confidence intervals overlapped to a high degree. The best of these models estimated $\varphi$ as 0.93 (SE $=$ $0.21,95 \% \mathrm{CI}: 0.53-1.00)$ for females and 0.89 ( $\mathrm{SE}=0.05,95 \%$ CI: 0.79-0.98) for males. Time variant models for $\varphi$ were also poorly supported $(\triangle \mathrm{AICc}>7.12)$ : in the best-supported version, estimates of $\varphi$ ranged from $0.82(\mathrm{SE}=0.13)$ to $1.0(\mathrm{SE}=0.22)$.

\section{Discussion}

Sex-based differences in migratory behavior are common in many vertebrates including oceanic sharks (Sims, 2005), and therefore can lead to potentially differential mortality rates. Empirically collected data from white shark aggregation sites suggest a skewed sex ratio favoring males coupled with different

TABLE 1 | Model selection results for models representing hypotheses about sex-based differences in survival.

\begin{tabular}{lcccc}
\hline Model & $\boldsymbol{K}$ & AICc & $\Delta$ AICc & $\boldsymbol{w}_{\boldsymbol{i}}$ \\
\hline$\varphi() p.(\operatorname{sex}) \pi(.) \delta(\operatorname{sex}+\mathrm{t})$ & 11 & 401.70 & 0.00 & 0.90 \\
$\varphi(\operatorname{sex}) p(\operatorname{sex}) \pi(.) \delta(\operatorname{sex}+\mathrm{t})^{\star}$ & 12 & 403.71 & 2.01 & - \\
$\varphi() p.(\operatorname{sex}+\mathrm{t}) \pi(.) \delta(\operatorname{sex}+\mathrm{t})$ & 15 & 406.17 & 4.47 & 0.10
\end{tabular}

Selection is based on lowest $\triangle A / C c$ scores. Only the top 3 models whose $\Delta A / C c<5.00$ are presented. K represents the number of parameters. $w_{i}$ represents the relative weight of evidence for each model.

${ }^{*}$ Redundant model as defined by Burnham and Anderson (2002). 


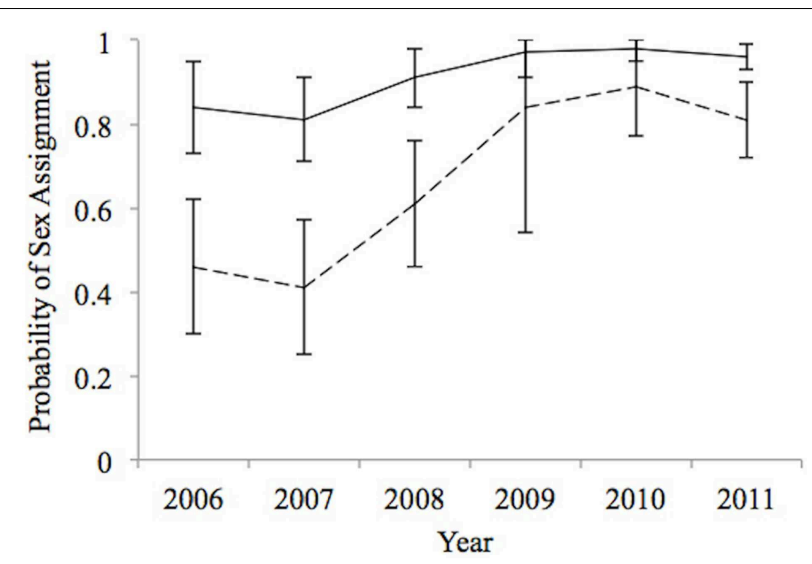

FIGURE 2 | Estimated probability of sex assignment from best-supported model for 2006-2011, which represents our ability ( \pm 1 SE) to unambiguously assigning sex (Male; -, Female; - -) to an unsexed shark on a given sampling occasion (year).

migratory patterns between sexes in white sharks in the NEP raised the possibility of higher mortality in mature females. Using mark-recapture data and a model that accounted for imperfect detection and imperfect sex assignment (Nichols et al., 2004), we found evidence of similar apparent survival rates for male and female sub-adult and adult white sharks off the coast of central California. Importantly, this similar apparent survival rate occurs despite a difference in the probability of capture between the sexes. Additionally, using this model, we were able to probabilistically assign sex to individuals of unknown sex to estimate the sex ratio in our dataset.

For sub-adult and adult white sharks sampled in known central California aggregation sites, the estimated annual apparent survival $(\varphi)$ was 0.90 (95\% CI: 0.81-0.98) for males and females during 2006-2011 based on empirical information from 199 individuals. White sharks can have a long life span (Andrews and Kerr, 2015; Hamady et al., 2014) and require surviving over a long time to become sexually mature. White sharks produce small litter sizes per reproductive cycle and gestation rates are likely long (12-18 months) and thus reproductive output is low per generation (Francis, 1996; Pratt, 1996). Therefore, the survival rates for sexually mature white sharks needs to be high if a population is to persist. The estimate reported here of 0.90 is comparable to those of 0.87 presented by Smith et al. (1998) and $0.81-0.92$ by Cortés (2002), though both of these prior estimates were based on limited information about the estimated longevity for the species. A high survival rate is not surprising since white sharks are long lived and low estimates of natural mortality are expected. However, given our estimate, annual recruitment of new individuals into the sub-adult class of white sharks would need to exceed $1-\varphi$ or $\geq 0.10$ (95\% CI: 0.02-0.19) to compensate for annual mortality and/or permanent emigration. Currently, quantification of recruitment rates to the sub-adult and adult demographic, numbers vital to population assessment models of any fisheries population, is unknown for white sharks. Furthermore, the processes and rate of recruitment involved in the ontogenetic shift from juvenile white sharks that are known to occur primarily to the south of Point Conception (Klimley, 1994; Weng et al., 2007b) to the central California sub-adult and adult habitat are poorly understood.

The estimated sex ratio in the central California sample population is 2.1 ( $\mathrm{SE}=0.05)$ males per female after sharks of unknown sex were probabilistically assigned to sex. Our adjusted estimate is closer to parity than the observed sex ratio of 3 known males for each known female in the raw dataset. It is also closer to that reported for white sharks in the Guadalupe Island group (sex ratio of 1.5 males per female, Nasby-Lucas and Domeier, 2012). Assuming a 1:1 sex ratio at birth, it is worth considering why sex ratios of sub-adults and adults favor males at both of these aggregation sites and whether the reported sex ratios are accurate. A lower proportion of females are detected in the central California population (compared to males) because females are more likely, on an annual basis, to be temporary emigrants, i.e., stay outside of our study area during some field seasons (Anderson and Pyle, 2003; Jorgensen et al., 2010; Domeier and Nasby-Lucas, 2012, 2013). This may potentially occur due to the reproductive physiological requirements of gestation (Robbins, 2007). That is, there may be advantages for gravid females to remain in the warmer oceanic habitat. However, this difference in TE alone cannot account for the observed sex ratio skew. If there is a true underlying 1:1 sex ratio, it stands to reason that initially an observed skew should reflect the sex difference in capture probability and over time (years) the observed sex ratio should trend toward parity as more females are cumulatively identified and added to the dataset. Yet over this 6-year study in central California and the 9-year study at Guadalupe Island, a disparate sex ratio favoring males has been maintained. Because we saw no difference in apparent survival (and therefore mortality) between males and females, the skewed sex ratio likely indicates either a higher mortality for females at an earlier life stage or that a large percentage of females are never observed.

The latter could occur in these locations if the time of year sampled and durations at each location observed favored detection of males, and miss a large percentage of the female population. However, independent data show that records of white shark predations at the southeast Farallon Islands decrease substantially after our sampling efforts in November (Klimley et al., 1992; Klimley and Anderson, 1996; Brown et al., 2010) and efforts at Año Nuevo Island and Tomales Point span the known coastal residency period. However, the observations to date at Año Nuevo Island in this data set are limited and efforts to increase sampling at this location have occurred.

Alternatively, a large portion of the females in this population could remain in unknown locations, outside of the study sites making them impossible to observe. The finding of equivalent apparent survival $(\varphi)$ for males and females suggests that the individual females observed, return regularly though less frequently to the study area. That is, they likely do not permanently emigrate at a higher rate than males do. Thus, any unaccounted for females would likely have to remain completely outside of the coastal study area, either offshore in the pelagic environment, or at undiscovered coastal aggregation sites with disproportionately higher numbers of females. While to date, no data exist to support these possibilities, they can also not be ruled out. 
In this study, despite equivalent estimates of $\varphi$, males and females had a marked difference in estimated capture probabilities $(p)$. The top model estimated $p$ as roughly twice as high for males than for females. TE by females is likely responsible for some of the difference. It is also possible that females might behave differently than males and simply be harder to detect with our methods. The extent to which these factors cause the discrepancy is the topic of future analyses using acoustic tagging data in concert with visual mark recapture.

Although we found apparent survival to be the same for both sexes and throughout our study period in central California, survival estimates for sub-adult and adult white sharks at Guadalupe Island, Mexico, based on Cormack-Jolly-Seber models, provided evidence that $\varphi$ varies among years but not between sexes and ranged from $0.80(\mathrm{SE}=0.052)$ and $0.99(\mathrm{SE}=0.000)$ (Sosa-Nishizaki et al., 2012). However, potential methodological biases introduced by using photos from six body regions to identify an individual may have compromised the usefulness of these findings. Sharks that had $<6$ regions photographically recorded were considered "orphans" and not used for analyzing survival. If observations were obtained for all 6 regions at some later date, then these individuals were retroactively entered as being detected on previous occasions in the encounter history for these individuals (Nasby-Lucas and Domeier, 2012). This type of retroactive inclusion has been deemed inappropriate for testing for differences in survival between sexes due to potential biases (Nichols et al., 2004). In this scenario, infrequently observed individuals should have a higher chance of being "orphans" but never included in the dataset used for analysis. If the reason for fewer sightings were due to mortality of those individuals, then one would expect estimates of survival to be biased high.

Causes of mortality for sub-adult and adult white sharks are not well documented in the NEP. Like all sharks, white sharks are negatively buoyant and sink when they die, confounding opportunities to observe or obtain dead specimens and estimate natural mortality. Mortality may result from intraspecific aggression, wounds inflicted by marine mammals during foraging efforts, attacks by killer whales (Orcinus orca), or fisheries activities. Grievous wounds have been observed (especially in the gill region) on both sexes of white sharks, and based on their appearance the wounds were apparently inflicted by other white sharks (Kanive personal observation). It is reasonable to infer that some sharks are not able to survive severe intraspecific interactions, but the nature and importance of such interactions are poorly understood. The marine mammals that constitute their primary prey (Mirounga angustirostris, Zalophus californianus, Phoca vitulina) (Carlisle et al., 2012) are capable of defending themselves with their claws and teeth. Numerous wounds inflicted by these prey have been observed on the heads of white sharks (Kanive personal observation) and it is possible that white shark populations pay some foraging cost of predation (Brown and Kotler, 2004). Despite white sharks being a top predator, in 1997 a killer whale was observed preying on a white shark (Pyle et al., 1999), but the rate at which such interspecific interactions occur is very poorly understood.

Sharks within central California waters' cannot be targeted for sport fishing, as they are protected in California, and poaching of sub-adult and adult white sharks is considered to be rare, though catch reporting is likely influenced by incentives and laws. However, young of the year and juveniles are still incidentally caught south of Point Conception, CA in gill net fisheries (Lowe et al., 2012; Lyons et al., 2013) and numerous international and domestic fisheries operate pelagic and neritic long-lines, gill nets, and purse seines throughout the NEP, which can result in bycatch of white sharks, particularly smaller year classes such as juveniles and sub-adults.

In conclusion, gathering empirical population data that improves the capacity to assess white sharks can enhance the capacity to make management decisions for this population. We used a mark-recapture model, developed by Nichols et al. (2004), that is a viable means to estimate apparent survival and allow testing for potential differences in life history parameters between sexes for white shark populations and applicable to other taxa where imperfect sex assignment occurs. Our findings indicate that the central California group of NEP sharks has a survival rate of 0.90 that does not differ between sexes. Additionally, after accounting for imperfect sex assignment, we estimate that the sex ratio of observed white sharks over 6 years heavily favors males. It will be essential to address this finding in future population assessments or demographic analyses. Because data for vital rates of smaller length classes are still lacking, further work is required to evaluate whether recruitment in the population is adequate to replace sub-adult and adult white sharks that are lost to natural and fisheries mortality and/or permanent emigration in this population. The use of natural marks and improved methods for data collection used here along with other improved electronic technologies for monitoring animals in marine environments (Block et al., 2011) will allow for important advances in the understanding of the population dynamics of this species.

\section{Acknowledgments}

Funding was provided by the Monterey Bay Aquarium Foundation, Tagging of Pacific Pelagics (TOPP) (Moore Foundation) and Stanford University. We would like to thank R. Elliott, J. Fitzgerald, B. Becker, J. Barlow, T. Baty, A. Carlisle, K. Neff, J. Moskito, T. McMahon, G. Stauffer, T. Chambert, Rotella lab mates, S. and A. Neff, M. Jansen, A. Olson, L. Hennes, S. Parks, E. Partee, J. Mytkowicz, D. Young, R. Kochevar, K. Kappenman, M. Webb, M. Castleton, J. Cornelius, J. Soper, L. Rust, S. Allen, Bodega Marine Lab and P. King. We are grateful to the entire crew of R. S. V. Derek M. Baylis, as well as T. O’Leary for vessel support.

\section{Ethical Standards}

This project was conducted with permits from CDFG, MBNMS, GFNMS, NOAA, NPS and under the University of California, Davis animal care protocol 15024, the Stanford University animal care protocol 10765 and the Montana State University animal care protocol 2009-34.

\section{Supplementary Material}

The Supplementary Material for this article can be found online at: http://www.frontiersin.org/journal/10.3389/fmars. 2015.00019/abstract 


\section{References}

Anderson, S. D., Chapple, T. K., Jorgensen, S. J., Klimley, A. P., and Block, B. A. (2011). Long-term individual identification and site fidelity of white sharks, Carcharodon carcharias, off California using dorsal fins. Mar. Biol. 158, 1233-1237. doi: 10.1007/s00227-011-1643-5

Anderson, S. D., and Pyle, P. (2003). A temporal, sex-specific occurrence pattern among white sharks at the South Farallon Islands, California. Calif. Fish Game $89,96-101$.

Andrews, A. H., and Kerr, L. A. (2015). Validated age estimates for large white sharks of the northeastern Pacific Ocean: altered perceptions of vertebral growth shed light on complicated bomb $\Delta 14 \mathrm{C}$ results. Environ. Biol. Fish. 98, 971-978. doi: 10.1007/s10641-014-0326-8

Arnold, T. W. (2010). Uninformative Parameters and Model Selection Using Akaike's Information Criterion. J. Wildl. Manag. 74, 1175-1178. doi: 10.1111/j.1937-2817.2010.tb01236.x

Block, B. A., Jonsen, I. D., Jorgensen, S. J., Winship, A. J., Shaffer, S. A., Bograd, S. J., et al. (2011). Tracking apex marine predator movements in a dynamic ocean. Nature 475, 86-90. doi: 10.1038/nature10082

Boustany, A. M., Davis, S. F., Pyle, P., Anderson, S. D., Boeuf, B. J. L., and Block, B. A. (2002). Satellite tagging: Expanded niche for white sharks. Nature 415, 35-36. doi: 10.1038/415035b

Brown, A. C., Lee, D. E., Bradley, R. W., and Anderson, S. (2010). Dynamics of white shark predation on pinnipeds in California: effects of prey abundance. Copeia 2010, 232-238. doi: 10.1643/CE-08-012

Brown, J. S., and Kotler, B. P. (2004). Hazardous duty pay and the foraging cost of predation. Ecol. Lett. 7, 999-1014. doi: 10.1111/j.1461-0248.2004.00661.x

Burnham, K. P., and Anderson, D. R. (2002). Model Selection and MultiModel Inference: A Practical Information-Theoretic Approach. New York, NY: Springer.

Cailliet, G. M., Natanson, L. J., Weldon, B. A., and Ebert, D. A. (1985). Preliminary studies on the age and growth of the white shark, Carcharodon carcharias, using vertebral bands. Mem. South. Calif. Acad. Sci. 9, 49-60.

Carlisle, A. B., Kim, S. L., Semmens, B. X., Madigan, D. J., Jorgensen, S. J., Perle, C. R., et al. (2012). Using stable isotope analysis to understand the migration and trophic ecology of northeastern Pacific white sharks (Carcharodon carcharias). PLOS ONE 7:e30492. doi: 10.1371/journal.pone.0030492

Chapple, T. K., and Botsford, L. W. (2013). A comparison of linear demographic models and fraction of lifetime egg production for assessing sustainability in sharks. Conserv. Biol. 27, 560-568. doi: 10.1111/cobi.12053

Chapple, T. K., Jorgensen, S. J., Anderson, S. D., Kanive, P. E., Klimley, A. P., Botsford, L. W., et al. (2011). A first estimate of white shark, Carcharodon carcharias, abundance off Central California. Biol. Lett. 7, 581-583. doi: 10.1098/rsbl.2011.0124

Choquet, R., Lebreton, J.-D., Gimenez, O., Reboulet, A.-M., and Pradel, R. (2009). U-CARE: Utilities for performing goodness of fit tests and manipulating CApture-REcapture data. Ecography 32, 1071-1074. doi: 10.1111/j.16000587.2009.05968.x

Cormack, R. M. (1964). Estimates of survival from the sighting of marked animals. Biometrika 51, 429-438. doi: 10.1093/biomet/51.3-4.429

Cortés, E. (2002). Incorporating uncertainty into demographic modeling: application to shark populations and their conservation. Conserv. Biol. 16, 1048-1062. doi: 10.1046/j.1523-1739.2002.00423.x

Dewar, H., Eguchi, T., Hyde, J., Kinzey, D., Kohin, S., Moore, J., et al. (2013). Status review of the northeastern pacific population of white sharks (Carcharodon carcharias) under the endangered species act. Prep. NMFS Southwest Fish. Sci. Cent. Jolla CA. Available online at: http://www.fpir.noaa.gov/Library/ PRD/great_white_shark/ws_brt_status_review-final.pdf (Accessed January 13, 2014).

Domeier, M., and Nasby-Lucas, N. (2008). Migration patterns of white sharks Carcharodon carcharias tagged at Guadalupe Island, Mexico, and identification of an eastern Pacific shared offshore foraging area. Mar. Ecol. Prog. Ser. 370, 221-237. doi: 10.3354/meps07628

Domeier, M., and Nasby-Lucas, N. (2012). "Sex-specific migration patterns and sexual segregation of adult white sharks, Carcharodon carcharias, in the Northeastern Pacific," in Global Perspectives on the Biology and Life History of the White Shark (CRC Press), 133-146. Available online at: http://www. crcnetbase.com/doi/abs/10.1201/b11532-14 (Accessed March 5, 2013).
Domeier, M. L., and Nasby-Lucas, N. (2013). Two-year migration of adult female white sharks (Carcharodon carcharias) reveals widely separated nursery areas and conservation concerns. Anim. Biotelem. 1, 1-10. doi: 10.1186/20503385-1-2

Dulvy, N. K., Baum, J. K., Clarke, S., Compagno, L. J. V., Cortés, E., Domingo, A., et al. (2008). You can swim but you can't hide: the global status and conservation of oceanic pelagic sharks and rays. Aquat. Conserv. Mar. Freshw. Ecosyst. 18, 459-482. doi: 10.1002/aqc.975

Estes, J. A., Terborgh, J., Brashares, J. S., Power, M. E., Berger, J., Bond, W. J., et al. (2011). Trophic downgrading of planet earth. Science 333, 301-306. doi: 10.1126/science. 1205106

Ferretti, F., Worm, B., Britten, G. L., Heithaus, M. R., and Lotze, H. K. (2010). Patterns and ecosystem consequences of shark declines in the ocean. Ecol. Lett. 13, 1055-1071. doi: 10.1111/j.1461-0248.2010.01489.x

Francis, M. P. (1996). "Observations on a pregnant white shark with a review of reproductive biology," in Great White Sharks: The Biology of Carcharodon carcharias, eds A. P. Klimley and D. G. Ainley (San Diego, CA: Academic Press), 157-172.

Gubili, C., Bilgin, R., Kalkan, E., Karhan, S. Ü., Jones, C. S., Sims, D. W., et al. (2010). Antipodean white sharks on a Mediterranean walkabout? Historical dispersal leads to genetic discontinuity and an endangered anomalous population. Proc. R. Soc. Lond. B Biol. Sci. rspb20101856. doi: $10.1098 /$ rspb.2010.1856

Gubili, C., Duffy, C. A. J., Cliff, G., Wintner, S. P., Shivji, M., Chapman, D., et al. (2012). "Application of molecular genetics for conservation of the great White Shark, Carcharodon carcharius, L. 1758," in Global Perspectives on the Biology and Life History of the White Shark (CRC Press), 357-380. Available online at: http://www.crcnetbase.com/doi/abs/10.1201/b11532-16. doi: 10.1201/ b11532-28

Gubili, C., Johnson, R., Gennari, E., Oosthuizen, W. H., Kotze, D., Meÿer, M., et al. (2009). Concordance of genetic and fin photo identification in the great white shark, Carcharodon carcharias, off Mossel Bay, South Africa. Mar. Biol. 156, 2199-2207. doi: 10.1007/s00227-009-1233-y

Hamady, L. L., Natanson, L. J., Skomal, G. B., and Thorrold, S. R. (2014). Vertebral bomb radiocarbon suggests extreme longevity in white sharks. PLOS ONE 9:e84006. doi: 10.1371/journal.pone.0084006

Jolly, G. M. (1965). Explicit estimates from capture-recapture data with both death and immigration-stochastic model. Biometrika 52, 225-247. doi: 10.1093/biomet/52.1-2.225

Jorgensen, S., Chapple, T., Hoyos, M., Reeb, C., and Block, B. (2012a). "Connectivity among White Shark Coastal aggregation areas in the Northeastern Pacific," in Global Perspectives on the Biology and Life History of the White Shark (CRC Press), 159-168. Available online at: http://www.crcnetbase.com/doi/abs/ |penalty- \@M10.1201/b11532-16 (Accessed March 5, 2013).

Jorgensen, S. J., Arnoldi, N. S., Estess, E. E., Chapple, T. K., Rückert, M., Anderson, S. D., et al. (2012b). Eating or meeting? Cluster analysis reveals intricacies of white shark (Carcharodon carcharias) migration and offshore behavior. PLoS ONE 7:e47819. doi: 10.1371/journal.pone.0047819

Jorgensen, S. J., Reeb, C. A., Chapple, T. K., Anderson, S., Perle, C., Sommeran, V. R. S., et al. (2010). Philopatry and migration of pacific white sharks. Proc. R. Soc. B Biol. Sci. 277, 679-688. doi: 10.1098/rspb. 2009.1155

Kendall, W. L., Nichols, J. D., and Hines, J. E. (1997). Estimating temporary emigration using capture-recapture data with Pollock's robust design. Ecology 78, 563-578. doi: 10.2307/2266030

Klimley, A. P. (1985). The areal distribution and autoecology of the white shark, Carcharodon carcharias, of the west coast of North America. Mem. South. Calif. Acad. Sci. 9, 15-40.

Klimley, A. P. (1994). The predatory behavior of the white shark. Am. Sci. 82 , $122-133$.

Klimley, A. P., and Anderson, S. D. (1996). "Residency patterns of white sharks at the South Farallon Islands, California," in Great White Sharks: The Biology of Carcharodon carcharias, eds A. P. Klimley and D. G. Ainley (San Diego, CA: Academic Press), 365-374.

Klimley, A. P., Anderson, S. D., Pyle, P., and Henderson, R. P. (1992). Spatiotemporal patterns of white shark (Carcharodon carcharias) predation at the South Farallon Islands, California. Copeia 1992, 680-690. doi: $10.2307 / 1446143$ 
Lebreton, J.-D., Burnham, K. P., Clobert, J., and Anderson, D. R. (1992). Modeling survival and testing biological hypotheses using marked animals: a unified approach with case studies. Ecol. Monogr. 62, 67-118. doi: $10.2307 / 2937171$

Long, D. J., Hanni, K. D., Pyle, P., Roletto, J., Jones, R. E., and Bander, R. (1996). "White shark predation on four pinniped species in central California waters: geographic and temporal patterns inferred from wounded carcasses," in Great White Sharks: The Biology of Carcharodon carcharias, eds A. P. Klimley and D. G. Ainley (San Diego, CA: Academic Press), 263-274.

Lowe, C., Blasius, M., Jarvis, E., Mason, T., Goodmanlowe, G., and O'Sullivan, J. (2012). "Historic fishery interactions with white sharks in the Southern California Bight," in Global Perspectives on the Biology and Life History of the White Shark (CRC Press), 169-186. Available online at: http://www.crcnetbase.com/ doi/abs/10.1201/b11532-17 (Accessed March 5, 2013).

Lyons, K., Jarvis, E. T., Jorgensen, S. J., Weng, K., O’Sullivan, J., Winkler, C., et al. (2013). The degree and result of gillnet fishery interactions with juvenile white sharks in southern California assessed by fishery-independent and -dependent methods. Fish. Res. 147, 370-380. doi: 10.1016/j.fishres. 2013.07.009

McCosker, J. E., and Lea, R. N. (2006). White shark attacks upon humans in California and Oregon, 1993-2003. Proc. Calif. Acad. Sci. 57, 479.

Nasby-Lucas, N., and Domeier, M. (2012). "Use of photo identification to describe a white shark aggregation at Guadalupe Island, Mexico," in Global Perspectives on the Biology and Life History of the White Shark (CRC Press), 381-392. Available online at: http://www.crcnetbase.com/doi/abs/10.1201/b11532-29 (Accessed March 5, 2013).

Nichols, J. D., Kendall, W. L., Hines, J. E., and Spendelow, J. A. (2004). Estimation of sex-specific survival from capture-recapture data when sex is not always known. Ecology 85, 3192-3201. doi: 10.1890/03-0578

Pardini, A. T., Jones, C. S., Scholl, M. C., and Noble, L. R. (2000). Isolation and characterization of dinucleotide microsatellite loci in the Great White Shark, Carcharodon carcharias. Mol. Ecol. 9, 1176-1178. doi: 10.1046/j.1365294x.2000.00954-4.x

Pratt, H. L. (1996). "Reproduction in the male white shark," in Great White Sharks: The Biology of Carcharodon carcharias, eds A. P. Klimley and D. G. Ainley (San Diego, CA: Academic Press), 131-138.

Pyle, P., Schramm, M. J., Keiper, C., and Anderson, S. D. (1999). Predation on a white shark (Carcharodon carcharias) by a killer whale (Orcinus orca) and a possible case of competitive displacement. Mar. Mammal Sci. 15, 563-568. doi: 10.1111/j.1748-7692.1999.tb00822.x

Robbins, R. L. (2007). Environmental variables affecting the sexual segregation of great white sharks Carcharodon carcharias at the Neptune Islands South Australia. J. Fish Biol. 70, 1350-1364. doi: 10.1111/j.1095-8649.2007. 01414.x

Rotella, J. (2009). Estimating reproductive costs with multi-state mark-recapture models, multiple observable states, and temporary emigration. Model. Demogr. Process. Mark. Popul. 3, 157-172. doi: 10.1007/978-0-387-78151-8_7

Schaub, M., Gimenez, O., Schmidt, B. R., and Pradel, R. (2004). Estimating survival and temporary emigration in the multistate capture-recapture framework. Ecology 85, 2107-2113. doi: 10.1890/03-3110

Seber, G. A. F. (1965). A note on the multiple-recapture census. Biometrika 52, 249-259. doi: 10.1093/biomet/52.1-2.249
Sims, D. W. (2005). "Differences in habitat selection and reproductive strategies of male and female sharks," in Sexual Segregation in Vertebrates: Ecology of the Two Sexes, eds K. E. Ruckstuhl and P. Neuhaus (Cambridge: Cambridge University Press), 127-147.

Smith, S. E., Au, D. W., and Show, C. (1998). Intrinsic rebound potentials of 26 species of Pacific sharks. Mar. Freshw. Res. 49, 663-678. doi: 10.1071 /MF97135

Sosa-Nishizaki, O., Morales-Bojórquez, E., Nasby-Lucas, N., Oñate-González, E., and Domeier, M. (2012). "Problems with photo identification as a method of estimating abundance of White Sharks, Carcharodon carcharias," in Global Perspectives on the Biology and Life History of the White Shark, (CRC Press), 393-404. Available online at: http://www.crcnetbase.com/doi/abs/10. 1201/b11532-30 (Accessed March 5, 2013).

Tanaka, S., Kitamura, T., Mochizuki, T., and Kofuji, K. (2011). Age, growth and genetic status of the white shark (Carcharodon carcharias) from Kashima-nada, Japan. Mar. Freshw. Res. 62, 548-556. doi: 10.1071/ MF10130

Towner, A. V., Wcisel, M. A., Reisinger, R. R., Edwards, D., and Jewell, O. J. D. (2013). Gauging the threat: the first population estimate for White Sharks in South Africa using photo identification and automated software. PLoS ONE 8:e66035. doi: 10.1371/annotation/bb25e7cb-12f7-42e4 $-9 \mathrm{~d} 26-07 \mathrm{~b} 9 \mathrm{bda} 87 \mathrm{ecc}$

Uchida, S., Toda, M., Teshima, K., and Yano, K. (1996). "Pregnant white sharks and full-term embryos from Japan," in Great White Sharks: The Biology of Carcharodon carcharias, eds A. P. Klimley and D. G. Ainley (San Diego, CA: Academic Press), 139-155.

Weng, K., Boustany, A., Pyle, P., Anderson, S., Brown, A., and Block, B. (2007a). Migration and habitat of white sharks (Carcharodon carcharias) in the eastern Pacific Ocean. Mar. Biol. 152, 877-894. doi: 10.1007/s0 0227-007-0739-4

Weng, K. C., O'Sullivan, J. B., Lowe, C. G., Winkler, C. E., Dewar, H., and Block, B. A. (2007b). Movements, behavior and habitat preferences of juvenile white sharks Carcharodon carcharias in the eastern Pacific. Mar. Ecol. Prog. Ser. 338, 211-224. doi: 10.3354/meps338211

White, G. C., and Burnham, K. P. (1999). Program MARK: survival estimation from populations of marked animals. Bird Study 46, S120-S139. doi: $10.1080 / 00063659909477239$

Williams, B. K., Nichols, J. D., and Conroy, M. J. (2002). Analysis and Management of Animal Populations: Modeling, Estimation, and Decision Making. San Diego, CA: Academic Press.

Conflict of Interest Statement: The authors declare that the research was conducted in the absence of any commercial or financial relationships that could be construed as a potential conflict of interest.

Copyright $(\odot) 2015$ Kanive, Rotella, Jorgensen, Chapple, Anderson, Klimley and Block. This is an open-access article distributed under the terms of the Creative Commons Attribution License (CC BY). The use, distribution or reproduction in other forums is permitted, provided the original author(s) or licensor are credited and that the original publication in this journal is cited, in accordance with accepted academic practice. No use, distribution or reproduction is permitted which does not comply with these terms. 